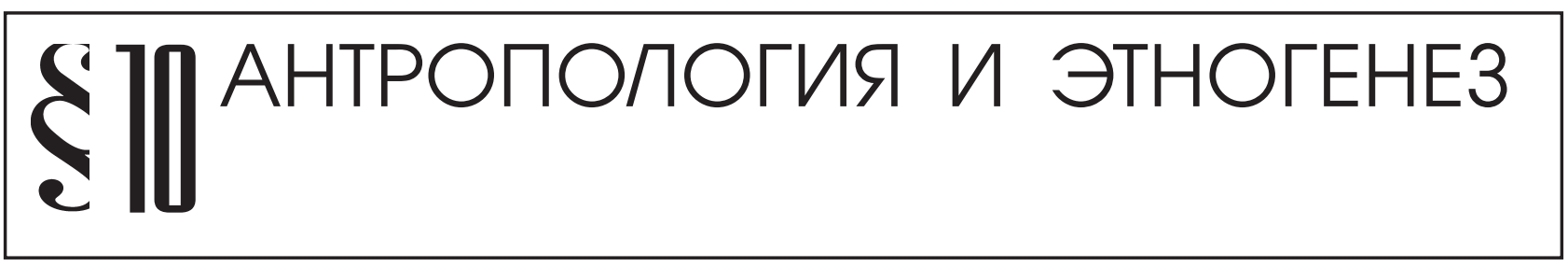

М.Ю. Барбашин

\title{
«СОВЕТСКОСТЬ» В ЭТНОСОЦИАЛЬНОМ ПРОСТРАНСТВЕ: ЭТНИЧЕСКИЕ И ИНСТИТУЦИОНАЛЬНЫЕ ПРОЦЕССЫ
}

\begin{abstract}
Аннотация: Анализируется влияние идеологии формирования “советского человека” на происходящуие в Советском Союзе этносоциильные процессы. Автор подчеркивает важность советскости как институциионального фона, в котором формировались этнические идентичности как титульных, так и нетитульных этносов. Применяя неоинституциональную методологию, автор подчеркивает, что советская идентификация использовалась индивидами с маргинальным этническим статусом, что замедляло этногенезисные процессы. Тесная институцииональная связь советскости с русским языком и идентичностью стала одной из причин того, что в транзитивный период десоветизация привела к частичной дерусификациии постсоветского этносоциального пространства.
\end{abstract}

Ключевые слова: Социология, этничность, советскость, институты, этногенез, конфликт, национальность, идеология, этнос, политика

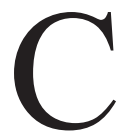
оветская идентичность обладала институциональными особенностями гражданской идентичности, так как формально не подразумевала привязку к этногруппе. В то же советская идентичность частично наслаивалась на этнопринадлежность, а частично заменяла ее, обладая некоторыми этнохарактеристиками.

Как предполагалось в общественном дискурсе [1], советский человек должен свободно владеть русским языком и быть приобщенным к советской и русской культуре. Обучение в вузах осуществлялось в основном на русском языке, поэтому выпускники школ с национальным уклоном, которые не имели удовлетворительной подготовки по русскому языку и литературе, обладали меньшей конкурентоспособностью по сравнению с абитуриентами, закончившими русские школы.

Повышение по сравнению с российской империей степени “русскости” жителей с другими этноидентификациями делало их уязвимыми к этноассимиляции. И наоборот, дерусификация этносоциума, высокая степень непринятия индивидов из смешанных семей и/или тех, кто утратил этнокультурные корни и не владеет родным языком, фактически страховала его от потенциального этнопоглощения.
Этногенез выстраивался в соответствии с согласием или несогласием как титульных, так и нетитульных этноэлит и интеллигенций на дискурсное влияние русского языка, поскольку в общественном сознании незнание или недостаточно свободное владение русским языком достаточно, чтобы не считаться русским.

В отличие от законодательного статуса коренных малочисленных народов [2], титульность предполагала институциональные критерии вертикальной взаимозависимости этносов. Титульность стала советской системой структурированного социально-группового неравенства, связанного с наличием или отсутствием определенной этничности.

Титульность проявлялась в том, что из нескольких этногрупп произвольно (иногда влияние оказывала этнопринадлежность того или иного руководящего чиновника) выбирались одна или две, в соответствии с названиями (“титулами”) которых формировались соответствующие республики.

Титульным этногруппам передавались административные привилегии как “смотрящим” за порядком. В двухсоставных республиках (Кабардино-Балкарии, Карачаево-Черкесии, Чечено-Ингушская Республика) выделялись титульные группы первого (кабардинцы 
и карачаевцы) и второго порядков (балкарцы и черкесы) [3]. У первых было больше административных возможностей, чем у вторых, но положение и тех, и других было лучше, чем нетитульных этносов. Суммарные возможности у титульных этносов превышали подобные блага у этнических аутсайдеров.

Важным неформальным институтом было представление, что в республиках первый секретарь должен быть титульной национальности. Этому правилу следовали до 1986 года, когда регионального лидера в Казахстане поменяли на русского функционера, и этнополитическая ситуация на окраинах Союза ухудшилась [4].

Титульная иерархизация этносов послужила основой формирования структурного конфликта между титульными и нетитульными этносами. Советским гражданам было сложно объяснить, почему, к примеру, кабардинцы и балкарцы получили политико-юридический статус титульности, а ногайцы или абазины были лишены такой возможности. Принятые органами власти решения было невозможно подвергнуть судебному пересмотру или внесудебному арбитражу. Даже обсуждение неравноправия этносов, не говоря уже о проявлении недовольства территориальным устройством, мог привести к репрессиям. Котел этнопроблем был запечатан институтами власти, а одной из институциональных проблем национальной политики была недоговоренность, недосказанность и расплывчатые формулировки советских вождей.

Титульность не менялась вне зависимости от демографических, культурных и социальных процессов. Единственным исключением стали депортации, включающие в себя как детитулизацию, так и поглощение территорий подозреваемых в нелояльности этносов соседними регионами.

Юридически статус титульности не был определенным. Хотя подразумевалось, что титульность отражает вклад этногруппы в социалистическое строительство, транспарентной и честной конкуренции не было. Как этносам, ставшим титульными, так и нетитульным этногруппам было непонятно, на каких исторических, территориальных, правовых или демографических основаниях одна этногруппа получила преимущества по отношению к остальным. Вне зависимости от коллективных усилий и/или индивидуальных успехов представителей нетитульных этносов получить титульность они не могли. Этноменьшинства, которые не дотягивали до титульного статуса (например, адыгейцы в Адыгейской автономии), самоут- верждались в политической и языковой сферах региона так, как если бы они этим статусом обладали [5].

Этнопретензии обладают “эффектом домино” повышение статуса одного субъекта провоцирует стремление остальных также повысить статус. "Естественно, обоюдное стремление каждого этноса к повышению своего политического статуса в рамках одного административного образования могло реализоваться лишь за счет других или не могло вообще. Доминирование одного народа неизбежно влечет за собой чувство ущемленности у других" [6].

В условиях доминирования советской идеологии политика титульного этноса по отношению к советским правилам межэтнического общежития была конформистской. Дерусификация могла быть только осознанным и маргинальным выбором на индивидуальном, но не на групповом уровне. Сознательный отказ от изучения русского языка и/или ограничение его использования для межэтнических контактов стали маркерами “этнической антисоветскости” в Прибалтике и на Западной Украине.

Как частично деэтнизированная идентичность советскость латентизировала этногенезисные процессы. Она канализировала недовольство этноаутсайдеров и нетитульных этногрупп в нейтральные идентификационные предпочтения. Она привлекала не только партийных карьеристов, но и граждан, не определившихся с этноидентичностью и/или не уверенных в идентификационном выборе. Этномаргиналы, которые могли бы сформировать этносубгруппы, выбирали советскость, поскольку она не была подвержена административным санкциям. Советскость была некоторой степенью защиты от этнодискриминации на бытовом уровне.

Советскость была “идентификационным щитом”, за которым скрывались все, кто не хотел и/или не был готов рисковать благополучием ради четкой этноидентификации.

Как показывают институциональные исследования [7], число сторонников новой идентификации вначале медленно возрастает, затем происходит скачкообразный подъем и постепенное снижение. Этот эмпирический феномен объясняется следующим образом: формирование идентичности рассматривается как легитимное параллельно росту “групповой плотности" [8]. Немногочисленность этногрупп создает им проблемы с легитимностью. Когда приверженцев этнопринадлежности немного, сложно объяснить другим этносам, ее “естественность” и “историческую укорененность” в этнокультурный ландшафт. 


\section{Политика и общество 3 (99) 2013}

Трансмиссия этноидентичностей была рестриктивной: перейти из одной этногруппы в другую было сложно не столько юридически, поскольку формальных запретов не было. Трудности носили бюрократический характер: требовалось внести соответствующие изменения в официальные документы. Российские историки [9] описывают исключительные ситуации быстрой смены этноидентичностей. После неофициального объявления руководством о депортации ряда народов в 1944 году, командование некоторых передовых военных подразделений меняло в документах этнопринадлежность своих подчиненных, чтобы вывести их из-под ареста.

Более распространенным способом трансмиссии этноидентичности стали межэтнические браки. Вопервых, при заключении брака супруги могли поменять фамилию - одну из основных аскриптивных этнохарактеристик, идентифицируемую чиновниками. Во-вторых, дети в межэтнических браках могли при получении паспорта выбрать как этнопринадлежность любого из родителей, так и другую этничность.

Этногенез зависел от социальной престижности той или иной системы этноидентификации, советской и русской идентичностей и от количества молодых людей, получающих паспорта. Хотя трансмиссия этничности происходила путем передачи детям фамилии и отчества главы семейства, родительское идентификационное давление было слабым. Они не тратили много сил, чтобы убедить детей принять этноидентичность, особенно если она была девиантизированной в общественном сознании.

Трансмиссия этноидентичности носила “имперфектный характер" [10] под давлением эрозии из-за особенностей применяющих ее агентов. Хотя русские родители при рождении записывали ребенка "русским", микроокружение индивида могло поощрять в нем формы поведения, соответствующие другой этничности. Социализация в украиноязычной среде и давление школьных сверстников вполне могли подвигнуть ребенка к осознанному выбору украинской этничности при получении паспорта.

“Советский человек” был для властей идентификационным вариантом, который вызывал меньшее число национальных проблем по сравнению с этнорадикалами. Когда отдельные националистические группы позиционировали себя как противников режима, это позволяло властям подготовиться к вызовам национализма. От территориально разрозненных “советских граждан”, которые для системы означали высшую степень лояльности, национальные проблемы не ожидались.
В системе межэтнических отношений отсутствовала институциональная возможность развития советской самоидентификации без знания русского языка. Но даже хорошего владения русским языком было недостаточно в случае подозрений властей в нелояльности гражданина или восприятия его действий как подрывных по отношению к системе. Советского гражданства можно было лишиться по политическим мотивам, и тогда человека высылали из страны.

Институциональная связь между русской идентичностью и советскостью стала причиной отсутствия интереса к изучению титульных языков как у русских в республиках, так и у титульных этногрупп. Партийная карьера республиканского чиновника зависела от его “советскости" и даже "русскости", т.е. от степени владения русским языком, знания партийного наследия, культуры и т.п. Многие родители школьников не видели смысла в изучении титульных языков, а категории приобщения к этнокультуре, обычаям, традициям выглядели несовременными и непрактичными. Даже в 2000-е гг. после десятилетия этнического подъема в республиках титульным языком владели немногие из русского населения [11].

Советскость поддерживалась пропагандой. Идеологизированность советской идентичности означала конформизм к системе, ее символам и институтам. Завязанная на политическую лояльность, советскость не стала институциональной заменой этноидентификаций. Слабый территориальный характер (хотя за рубежом выходцев из СССР идентифицировали с территорией) не позволял ей трансформироваться в национальную идентификацию.

Как территориальная идентичность советскость была привязана к государству, находящемуся почти полностью в пределах империи. Однако наличие некоторого территориального несоответствия между советскими и имперскими границами расшатывало связь советскости с территорией. Слабый территориальный характер советскости не позволил в 1980-е гг. использовать институциональные механизмы идентификационной опоры на историческую территорию, общность судьбы нации, традиции и пр. Исторический компонент и культурная глубина советскости подчеркивались редко, а ее социально-духовная связь с дореволюционной эпохой исследовалась только философами - евразийцами [12] в 1920-е гг., которые в советском дискурсе девиантизировались как “классово чуждые”.

Советскость воспринималась в общественном сознании как разрыв с дореволюционной историей, 
включая формирование национальной идентификации. Отсутствовали институциональные механизмы встраивания событий дореволюционного периода развития в когнитивную структуру советской идентичности. Большая часть дореволюционных событий и исторических фигур девальвировались сквозь призму классового противостояния. Хотя жесткость по отношению к принятию дореволюционного прошлого, выражению согласия с ним и/или проявления чувства гордости менялись в зависимости от политического момента, доминирующим эмоционально-когнитивным отношением было отрицание.

Результатом стала ламинальность общественного сознания. Дореволюционные и советские исторические образы не пересекались. Поскольку не было осознания идентификационного и территориального единства дореволюционной России и Советского Союза, политические нападки на советскую власть не рассматривались как ущерб сложившейся общности этносов. Распад Советского Союза ни элитами, ни академическим сообществом, ни населением не воспринимался как “геополитическая катастрофа" и разрушение исторической территории.

Исключением стали национальные радикалы, которые связывали негативность советского и досоветского периода. Как дореволюционная, так и советская Россия обвинялись, к примеру, адыгскими националистами в нарушениях исторических прав адыгов, а грузинские националисты рассматривали взаимодействие России с Грузией как бесконечный процесс “российской колонизации" [13].

В условиях доминирования диссидентских взглядов в общественном сознании советскость оказалась институционально уязвимой к критике как идентичность идеологических коллаборационистов. Допущенные ошибки в национальной политике создали вокруг власти "зону отчуждения".

Этноидентификационное якорение советскости и русскости стало причиной связи десоветизации с дерусификацией. Этногруппы, для которых советскость перестала служить “охранной грамотой” от дискриминации, стали чувствительными к новым возможностям. Для них отрицание советского прошлого прошло относительно легко.

Как только привлекательность советскости снизилась и для элит, и для большинства населения, как только началась десоветизация в политическом и экономической сферах, активизировались этногенезисные процессы.

\section{Библиография:}

1. Административно-территориальные преобразования в Кабардино-Балкарии. История и современность. Нальчик: Эль-Фа. 2000.

2. Бгажноков Б.Х., Шогенов А.А. Кризис национальных языков России. Языки народов России: перспективы развития. Материалы международного семинара. Элиста. 2000.

3. Гаджиев А. С. Великий русский язык - средство межнационального общения и приобщения народов Дагестана к достижениям научно-технической революции. Махачкала. 1981.

4. Губогло М.Н. Предпосылки изучения современной этнополитической ситуации в СССР // Национальные процессы в СССР. М.: Наука. 1991.

5. Кубов Ч. Ч. Деятельность КПСС по созданию и укреплению советской национальной государственности адыгейского народа // Сборник статей по истории Адыгеи: советский период. Майкоп, 1967.

6. Марченко Г. В. Государственная и национальная политика на Северном Кавказе (20-е - 40-е гг. XX в.). Ростов-на-Дону: Издательство СКНЦ ВШ. 2002.

7. Соколовский С. В. Понятие “этническое меньшинство" и “малочисленный народ” в социальных науках // Подходы к изучению этнической идентичности. М. 1994.

8. Такушинов Ш. Н. Причины этнополитических конфликтов в многонациональных регионах // Социальный порядок и толерантность. Сборник тезисов III Всероссийской научной конференции 30-31 мая 2002 г. Часть 2. Краснодар. 2002.

9. Трубецкой Н. С. Наследие Чингисхана. М.: Эксмо, 2007.

10. Чумбуридзе Д. Национально-освободительная борьба грузинского народа в начале XX века: 1918-1921 годы. Тбилиси. 2003.

11. Baum J. A. C. and Powell W. W. 1995. Cultivating an institutional ecology of organizations: Comment on Hannan, Carroll, Dudon, and Torres // American Sociological Review, 60, pp. 529-538.

12. Powell G. B. 1982. Contemporary Democracies: Participation, Stability, and Violence (Cambridge: Harvard University Press).

13. Zucker L. G. 1988. Where do institutional patterns come from? Organizations as actors in social systems // Institutional Patterns and Organizations: Culture and Environment, ed. by L. G. Zucker (Cambridge, MA: Ballinger), pp. 23-49. 


\section{Политика и общество 3 (99) • 2013}

\section{References (transliteration):}

1. Bgazhnokov B.Kh., Shogenov A.A. Krizis natsional'nykh yazykov Rossii. Yazyki narodov Rossii: perspektivy razvitiya. Materialy mezhdunarodnogo seminara. Elista. 2000.

2. Gadzhiev A. S. Velikiy russkiy yazyk - sredstvo mezhnatsional'nogo obshcheniya i priobshcheniya narodov Dagestana $\mathrm{k}$ dostizheniyam nauchno-tekhnicheskoy revolyutsii. Makhachkala. 1981.

3. Guboglo M.N. Predposylki izucheniya sovremennoy etnopoliticheskoy situatsii v SSSR // Natsional'nye protsessy v SSSR. M.: Nauka. 1991.

4. Kubov Ch. Ch. Deyatel'nost' KPSS po sozdaniyu i ukrepleniyu sovetskoy natsional'noy gosudarstvennosti adygeyskogo naroda // Sbornik statey po istorii Adygei: sovetskiy period. Maykop, 1967.

5. Marchenko G. V. Gosudarstvennaya i natsional'naya politika na Severnom Kavkaze (20-e-40-e gg. XX v.). Rostov-na-Donu: Izdatel'stvo SKNTs VSh. 2002.

6. Sokolovskiy S. V. Ponyatie "etnicheskoe men'shinstvo" i “malochislennyy narod” v sotsial'nykh naukakh // Podkhody k izucheniyu etnicheskoy identichnosti. M. 1994.
7. Takushinov Sh. N. Prichiny etnopoliticheskikh konfliktov $\mathrm{v}$ mnogonatsional'nykh regionakh // Sotsial'nyy poryadok i tolerantnost'. Sbornik tezisov III Vserossiyskoy nauchnoy konferentsii 30-31 maya 2002 g. Chast' 2. Krasnodar. 2002.

8. Trubetskoy N. S. Nasledie Chingiskhana. M.: Eksmo, 2007.

9. Chumburidze D. Natsional'no-osvoboditel'naya bor'ba gruzinskogo naroda v nachale XX veka: 19181921 gody. Tbilisi. 2003.

10. Baum J. A. C. and Powell W. W. 1995. Cultivating an institutional ecology of organizations: Comment on Hannan, Carroll, Dudon, and Torres // American Sociological Review, 60, pp. 529-538.

11. Powell G. B. 1982. Contemporary Democracies: Participation, Stability, and Violence (Cambridge: Harvard University Press).

12. Zucker L. G. 1988. Where do institutional patterns come from? Organizations as actors in social systems // Institutional Patterns and Organizations: Culture and Environment, ed. by L. G. Zucker (Cambridge, MA: Ballinger), pp. 23-49. 